Curr Opin Virol. 2014 August ; 0: 40-46. doi:10.1016/j.coviro.2014.03.015.

\title{
Cytomegalovirus microRNAs
}

\author{
Lauren Hook ${ }^{1}$, Meaghan Hancock ${ }^{1}$, Igor Landais ${ }^{1}$, Robert Grabski ${ }^{2}$, William Britt ${ }^{2}$, and Jay \\ A. Nelson ${ }^{1}$ \\ 1VGTI, OHSU West Campus, 505 NW 185th Avenue, Beaverton, OR, 97006, USA \\ ${ }^{2}$ Department of Pediatrics, University of Alabama, Birmingham, AL, 35294 USA
}

\begin{abstract}
The discovery that animals, plants and DNA viruses encode microRNAs (miRNAs) has transformed our understanding of the regulation of gene expression. miRNAs are ubiquitous small non-coding RNAs that regulate gene expression post-transcriptionally, generally by binding to sites within the 3' untranslated regions (UTR) of messenger RNA (mRNA) transcripts. To date, over 250 viral miRNAs have been identified primarily in members of the herpesvirus family. These viral miRNAs target both viral and cellular genes in order to regulate viral replication, the establishment and maintenance of viral latency, cell survival, and innate and adaptive immunity. This review will focus on our current knowledge of the targets and functions of human cytomegalovirus (HCMV) miRNAs and their functional equivalents in other herpesviruses.
\end{abstract}

\section{INTRODUCTION}

Since the discovery of the first miRNA in Caenorhabditis elegans, this family of small noncoding RNAs has expanded very rapidly, aided by the development of sensitive highthroughput identification techniques. miRNAs are generated from single-stranded, hairpinforming precursors that are sequentially cleaved by specialized enzymes, Drosha and Dicer. After incorporation into the RNA-induced Silencing Complex (RISC), miRNAs posttranscriptionally regulate cellular gene expression through the binding of RISC to the mRNA target via partial complementarity. Of particular importance is the seed sequence, a 6-8 residues stretch located between nucleotides 2 and 8 of the miRNA [1]. Partial pairing between a miRNA and the mRNA target leads to translational repression, mRNA decay or both. The miRNA target sites in mRNAs are most commonly located in the 3' UTR, although sites in the 5' UTR and the coding sequence have also been observed [1,2].

In addition to plants and animals, miRNAs have been identified in a number of doublestranded, nuclear-replicating DNA viruses. Of the reported 250+ virally encoded miRNAs, the vast majority is encoded by herpesviruses (www.mirbase.org). Little sequence

Corresponding author: Nelson, Jay A. (nelsonj@ohsu.edu) Phone number: +1-503-418-2710.

Publisher's Disclaimer: This is a PDF file of an unedited manuscript that has been accepted for publication. As a service to our customers we are providing this early version of the manuscript. The manuscript will undergo copyediting, typesetting, and review of the resulting proof before it is published in its final citable form. Please note that during the production process errors may be discovered which could affect the content, and all legal disclaimers that apply to the journal pertain.

Publisher's Disclaimer: () 2014 Elsevier B.V. All rights reserved. 
conservation exists among miRNAs within herpesvirus subfamilies [3-11]. However, the consensus in the field is that herpesvirus miRNAs share similar functions, as they have the potential to target the same gene using different target sites or closely related genes belonging to a shared pathway or process [12-15].

In this review, we will illustrate the biology, pleiotropic roles and challenges to our understanding of viral miRNAs by focusing on human cytomegalovirus miRNAs and their functional equivalents in other herpesviruses.

\section{HUMAN CYTOMEGALOVIRUS ENCODED MIRNAS}

Using a combination of direct cloning, bioinformatics and next-generation sequencing, a number of studies, including our own, have identified miRNAs encoded by HCMV in lytically infected fibroblasts [4-6,10]. A total of $24 \mathrm{HCMV}$-encoded miRNAs have been identified from the 13 pre-miRs: miR-UL22A-1, miR-UL36-1, miR-UL59-1, miR-UL112-1, miR-UL148D-1, miR-US4-1, miR-US5-1, miR-US5-2, miR-US22-1, miR-US25-1, miRUS25-2, miR-US29-1, and miRUS33-1. Unlike the miRNAs encoded by the $\alpha-$ and $\gamma$ herpesviruses, which are found clustered in regions of the genome associated with latent gene expression, the HCMV-encoded miRNAs are located throughout the viral genome as both single miRNAs and small clusters [4-6,10]. Many are encoded in intergenic regions, while miR-UL36-1 is encoded within the spliced intron of a coding gene [5]. A number of the miRNAs are encoded within open reading frames (ORFs) or 3' UTRs of genes [3,5]. miR-UL112-1 is encoded directly antisense to the viral uracil DNA glycosylase gene UL114, which could theoretically lead to the cleavage of the transcript and negative regulation of the gene $[3,5,16]$. While one group reported that miR-UL112-1 was able to cleave the UL114 transcript, studies by our group found that the mRNA was resistant to cleavage [16](unpublished observation). In contrast, miR-UL112-1 was able to target fully complementary sequences placed in luciferase reporter constructs, suggesting that flanking sequences within UL114 protect the sequence from miRNA directed cleavage (unpublished observation). In addition, studies from our lab demonstrated that miR-US5-1 and miRUS5-2 that are encoded directly antisense to the 3' UTR of the US7 gene downregulate its expression in a synergistic manner [15]. Surprisingly, this is accomplished through three functional miRNA binding sites, including two fully complementary sites antisense to the miRNA loci and one additional imperfectly matched site. This finding underscores the importance of evaluating the contribution of multiple miRNAs on gene regulation [15].

\section{IDENTIFYING TARGETS OF MIRNAS}

Ascribing functions to miRNAs is made difficult by the fact that each miRNA is predicted to target upwards of 100 genes and can do so through seemingly promiscuous targeting. A number of bioinformatic prediction algorithms have been developed based on complementarity between the miRNA of interest and sites within the 3' UTRs of mRNA transcripts, however, these often lead to high levels of false positives. In addition, many of these algorithms rely upon sequence conservation across species, and thus cannot accurately predict targets for non-conserved viral miRNAs like those of the herpesvirus family [3-11]. Experimental techniques including microarray $[12]$ and SILAC $[17,18]$ have been used to 
identify targeted transcripts and proteins respectively, that are differentially expressed upon the exogenous addition of the miRNA of interest or anti-sense inhibitors to the miRNA [18]. Recently, biochemical approaches based on RISC immunoprecipitation (RIP), including RIP-Chip, PAR-CLIP, and HITS-CLIP, have been developed to directly identify targeted transcripts incorporated into the RISC complex [2,13,19-26]. These approaches usually identify transcripts containing seed matches (upwards of 75\%) and experimental validation has been exceptionally high compared with bioinformatics approaches $[13,27,28]$.

The next sections will focus on our current knowledge of the targets and functions of HCMV and other herpesvirus miRNAs. These data are summarized in Table 1 and Fig. 1.

\section{HCMV MIRNAS TARGET VIRAL GENES miR-UL112-1 targets HCMV IE1}

Our group used a comparative bioinformatics-based approach to identify transcripts regulated by HCMV miRNAs [20]. A cluster of three potential targets for miR-UL112-1 were identified within the major immediate early (MIE) region of the virus. The MIE region encodes for regulatory proteins that coordinate viral gene expression during infection, including the major trans-activator IE72 (also known as IE1). Disruption of IE72 in the context of low multiplicity infections results in a significant attenuation of viral replication [29]. Expression of miRUL112-1 in combination with a vector containing the MIE region significantly reduced IE72 expression. HCMV DNA replication was inhibited up to 5-fold in cells that had been transfected with miR-UL112-1 mimic prior to infection, indicating that expression of miR-UL112-1 can attenuate replication of HCMV and has important implications for latency control of HCMV [20]. Moreover, mutant viruses unable to express miR-UL112-1 or that encoded IE1 lacking the miR-UL112-1 target sites expressed higher levels of IE1 protein during infection [30]. Subsequently, Murphy et al. [30] identified miRNA target sites within the 3' UTRs of four herpesvirus IE transactivators: ICP0 of HSV-1; IE1 of HCMV; BZLF1 and BRLF1 of EBV; and Rta and Zta of KSHV. The fact that several herpesviruses express miRNAs that target their own trans-activator genes suggests that these viruses may utilize miRNAs to establish and/or maintain viral latency (Fig. 1A) [20,30,31]. Both EBV and KSHV miRNAs have been found to target additional viral and cellular genes involved in the maintenance of viral latency, underscoring the importance of these non-immunogenic RNAs in the viral lifecycle $[13,28]$.

\section{miR-UL112-1 targets the HCMV uracil DNA glycosylase}

miR-UL112-1 has been reported to target the viral uracil DNA glycosylase (UL114) encoded antisense to miR-UL112-1 [16]. Uracil DNA glycosylase associates with the DNA polymerase processing factor ppUL44 to increase the efficacy of both $\mathrm{E}$ and $\mathrm{L}$ phase viral DNA synthesis [32]. As miR-UL112-1-mediated reduction of UL114 protein has a moderate effect on the ability of the virus to properly excise uracil residues from viral DNA, miRUL112-1 may function to inhibit DNA replication during the establishment of latency (Fig. 1A) [16]. 
miR-US5-1 and miR-US5-2 target the HCMV US7 gene

As developed above, miR-US5-1 and miR-US5-2 are encoded antisense to the 3' UTR of US7 and are able to downregulate the gene in a highly synergistic manner [15]. These observations were the first evidence that HCMV miRNAs can act cooperatively to enhance the downregulation of targets. Viruses with mutations that inactivate miR-US5-1 and/or miR-US5-2 displayed an increase in US7 protein expression. Although the exact function of US7 is currently unknown, the ORF is located in a region that encodes proteins involved in MHC downregulation [33]. Since RhCMV encodes a miR-US5-2 homologue that also targets the RhCMV US7 homologue, the conservation suggests that regulation of this gene is important in the lifecycle of the virus [11].

\section{HCMV miRNAS TARGET CELLULAR GENES INVOLVED IN CELL CYCLE CONTROL}

A combination of RIP-Chip and streptavidin bead pull-down of biotinylated miRNA approaches identified cellular mRNA targets of HCMV miR-US25-1 [20]. Among these targets were multiple mRNAs encoding proteins involved in cell cycle control, including cyclin E2, BRCC3, EID1, MAPRE2, CD147 and histone proteins (Table 1, Fig. 1B). Surprisingly, most cellular transcripts enriched in these experiments had miR-US25-1 seed sequences located in the 5' UTR rather than the 3' UTR, however the functional significance of this finding is unclear. miR-US25-1 mutant virus infection resulted in a significant increase in cyclin E2 protein compared to WT [20]. Like HCMV, both EBV and KSHV miRNAs also target genes involved in cell cycle control, however the functional consequences of this targeting await investigation $[13,28]$.

\section{HCMV miRNAS TARGET CELLULAR GENES INVOLVED IN IMMUNE EVASION}

HCMV miR-UL112-1 targets MICB

One of the first HCMV miRNA cellular targets identified was the MHC I polypeptide related sequence B (MICB) [34], a stress-induced ligand for the NK cell activating receptor NKG2D (Fig. 1C) [35]. In addition, both EBV and KSHV encode miRNAs that directly target this transcript. KSHV also encodes miRNAs that target the activation-induced cytidine deaminase (AID) gene, a trigger of the DNA damage response pathway leading to increased expression of NKG2D ligands [36], furthering the hypothesis that despite absence of conservation, miRNAs from different viruses target the same genes and pathways [14]. Expression of miR-UL112-1 in tumor cell lines resulted in down-regulation of MICB surface expression, and WT but not mutant miR-UL112-1 viruses more efficiently downregulated MICB surface expression, which resulted in decreased NK cell killing.

MICB protein levels are also modulated by at least nine cellular miRNAs [14,37,38]. The miR-UL112-1 binding site overlaps that of the cellular miRNA miR-373, which may prevent this site from being mutated by the host. Combining the cellular miRNA miR-376a with the viral miR-UL112-1 resulted in synergistic down-regulation of MICB [38]. The proximity of the cellular and viral miRNA target sites (24 nucleotides from the 5 ' ends of 
each miRNA) was essential to the synergistic response, since moving the sites further from one another resulted in only additive down-regulation of MICB. These data suggest that HCMV may have evolved to cooperate with cellular miRNAs to synergistically downregulate target genes.

\section{HCMV miR-UL148D-1 targets the chemo-attractant cytokine RANTES}

While investigating determinants of virulence between clinical HCMV strain Toledo and attenuated strain AD169, Kim et al. [39] observed that the levels of RANTES mRNA remained low to undetectable in cells infected with Toledo yet gradually increased and then peaked at $48 \mathrm{hpi}$ in cells infected with AD169. The major difference between the two strains is that Toledo contains a 15-kb DNA segment missing from AD169 that encodes 19 ORFs and one miRNA, miR-148D-1. The authors found that miR-UL148D-1 directly targets the RANTES mRNA through a site in the 3' UTR leading to degradation and a marked reduction in RANTES secretion from CMV infected fibroblasts (Fig. 1C). RANTES recruits immune cells including T cells, eosinophils, and basophils to limit viral infections, therefore a miRNA that targets and degrades RANTES mRNA would likely potentiate infection, providing an intriguing hypothesis for the increased virulence of clinical strains like Toledo [39].

\section{HCMV miR-UL112-1 TARGETS BCLAF1}

The cellular protein BclAF1 was recently identified as a HCMV restriction factor that is targeted by the viral protein pp71 early during infection [18]. BclAF1 (Bcl-2 associated factor 1) is a nuclear protein implicated in a variety of processes including apoptosis, transcriptional regulation, and RNA processing and export from the nucleus. A SILAC screen identified BclAF1 as a potential target of miRUL112-1 and a target site was identified within the 3' UTR of BclAF1 [18]. Mutation of this site blocked the effect of miR-UL112-1 in luciferase reporter assays, and BclAF1 levels were substantially reduced in cells expressing miRUL112-1. Confirming the importance of miR-UL112-1 targeting of BclAF1, a cell line expressing BclAF1 lacking the miR-UL112-1 target site prevented HCMV spread in culture. Interestingly, Zieglebauer et al. [12] found that BclAF1 is targeted by multiple KSHV miRNAs during chemically induced lytic infection. Antagomirs directed against these miRNAs resulted in increased BclAF1 expression and decreased virion production, suggesting that BclAF1 is also a KSHV restriction factor. However, the mechanism by which BclAF1 exerts its effect on HCMV and KSHV infection is unclear. One interesting observation is that BclAF1 is a key inducer of autophagy and autophagic cell death in multiple myeloma [40]. In these cells, excessive induction of autophagy has been linked to pressures on protein handling pathways resulting from the accumulation of misfolded immunoglobulin [41]. Since viral productive infection typically exerts similar stress on protein handling pathways (for review, [42]), HCMV and KSHV miRNAs might target BclAF1 to prevent autophagic death of the infected cells. 


\section{HCMV MIRNAS TARGET SEVERAL MEMBERS OF THE SECRETORY PATHWAY}

Building on the comprehensive miR-US25-1 RISC-IP analysis that led to the identification of cell cycle control genes, Pavelin et al. [26] demonstrated that miR-US25-1 targets the endosomal acidification complex component ATP6V0C and validated five other targeted genes (Table 1, Fig. 1D). This study compared RISC-IP analysis from WT and miR-US25-1 mutant viruses for thorough confirmation of potential targets. A functional target site was identified within the ATP6V0C ORF, identifying yet another novel targeting mechanism utilized by miR-US25-1. Interestingly, knockdown of ATP6V0C, or other components of the same endosomal acidification complex, blocked replication of HCMV, suggesting that targeting this protein may be important for limiting viral replication during latency or alternatively blocking an innate immune response [26].

A very recent work by our lab demonstrated that multiple HCMV miRNAs cooperatively target multiple genes within the endocytic pathway in order to fully block the pathway function. [43]. Using both biochemical and in silico analyses, we observed that multiple members of the endocytic pathway including VAMP3, RAB5C, RAB11A, SNAP23, and CDC42 are targeted by HCMV miR-UL112-1, miR-US5-1, and miR-US5-2 (Table 1, Fig. 1D). Mutation of these HCMV miRNAs in the virus resulted in the malformation of the virion assembly complex during infection (Fig. 2), while transfection of the HCMV miRNAs or siRNAs directed against RAB5C, RAB11A, SNAP23, and CDC42 resulted in the formation of distinct structures resembling the assembly complex. Analysis of the mutant virus released from infected cells revealed a 2-log reduction of supernatant virus and a 3-log increase in the production of defective particles, indicating that miRNAs coordinately regulate the endocytic pathway to form the VAC in order to efficiently produce infectious virus. In addition, expression of miRs UL112-1, miRUS5-1, and miR-US5-2 significantly reduced the release of inflammatory cytokines in cells stimulated by LPS or infected with the triple miRNA mutant virus. Taken together these data suggest that HCMV miRNAs cooperatively target multiple genes belonging to the cellular secretory pathway to limit cytokine release and aid in the proper assembly and release of virus [43]. Both EBV and KSHV miRNAs also target components of intracellular transport and endosomal vesicles [13,28]. The functional consequences of this targeting are still unclear, but like HCMV, intracellular transport may be blocked to limit innate immune response, apoptosis and/or favor viral replication.

\section{CONCLUSIONS}

While targets of herpesvirus miRNAs are being uncovered, much remains unknown about their functions during infection. What is clear is that herpesviruses utilize miRNAs to regulate their own genes as well as those of the host cell during infection. Despite lacking sequence conservation, miRNAs encoded by different herpesviruses appear to be performing similar functions by targeting the same pathways or processes. Often, many of these functions are also performed by viral proteins, illustrating another example of redundancy/ control that has come to be expected of herpesviruses. While biochemical approaches, 
including RIP-Chip, PAR-CLIP, and HITS-CLIP have been invaluable in determining potential miRNA targets and will likely aid in furthering functional characterization, not until the contribution of all miRNAs on a given pathway or process is determined, will we truly understand their functional significance.

\section{Acknowledgments}

This review was supported by NIH/NIAID grant AI021640 to J.A.N. We would like to thank A. Townsend for help with the illustrations. We acknowledge the important contribution of those researchers whose work was not fully cited due to space limitations.

\section{REFERENCES AND RECOMMENDED READING}

Papers of particular interest, published within the period of review, have been highlighted as:

* of special interest

** of outstanding interest

1. Bartel DP. MicroRNAs: target recognition and regulatory functions. Cell. 2009; 136:215-233. [PubMed: 19167326]

2*. Grey F, Tirabassi R, Meyers H, Wu G, McWeeney S, Hook L, Nelson JA. A viral microRNA down-regulates multiple cell cycle genes through mRNA 5'UTRs. PLoS Pathog. 2010; 6:e1000967. The first study to use RIP-Chip to identify the targetome of a HCMV miRNA. [PubMed: 20585629]

3*. Pfeffer S, Zavolan M, Grasser FA, Chien M, Russo JJ, Ju J, John B, Enright AJ, Marks D, Sander C, et al. Identification of virus-encoded microRNAs. Science. 2004; 304:734-736. The first study to identify miRNAs in a member of the herpesvirus family, EBV, using cloning and molecular biology approaches. [PubMed: 15118162]

4*. Pfeffer S, Sewer A, Lagos-Quintana M, Sheridan R, Sander C, Grasser FA, van Dyk LF, Ho CK, Shuman S, Chien M, et al. Identification of microRNAs of the herpesvirus family. Nat Methods. 2005; 2:269-276. This study identified miRNAs expressed by several herpesviruses including KSHV, MHV68 and HCMV using bioinformatics and small RNA cloning approaches. [PubMed: 15782219]

5*. Grey F, Antoniewicz A, Allen E, Saugstad J, McShea A, Carrington JC, Nelson J. Identification and characterization of human cytomegalovirus-encoded microRNAs. J Virol. 2005; 79:1209512099. One of the first studies to identify and characterize HCMV miRNAs using comparative genomics, bioinformatics and molecular biology approaches. [PubMed: 16140786]

6. Dunn W, Trang P, Zhong Q, Yang E, van Belle C, Liu F. Human cytomegalovirus expresses novel microRNAs during productive viral infection. Cell Microbiol. 2005; 7:1684-1695. [PubMed: 16207254]

7. Buck AH, Santoyo-Lopez J, Robertson KA, Kumar DS, Reczko M, Ghazal P. Discrete clusters of virus-encoded micrornas are associated with complementary strands of the genome and the 7.2kilobase stable intron in murine cytomegalovirus. J Virol. 2007; 81:13761-13770. [PubMed: 17928340]

8. Dolken L, Perot J, Cognat V, Alioua A, John M, Soutschek J, Ruzsics Z, Koszinowski U, Voinnet $\mathrm{O}$, Pfeffer S. Mouse cytomegalovirus microRNAs dominate the cellular small RNA profile during lytic infection and show features of posttranscriptional regulation. J Virol. 2007; 81:13771-13782. [PubMed: 17942535]

9. Meyer C, Grey F, Kreklywich CN, Andoh TF, Tirabassi RS, Orloff SL, Streblow DN. Cytomegalovirus microRNA expression is tissue specific and is associated with persistence. $\mathrm{J}$ Virol. 2011; 85:378-389. [PubMed: 20980502]

$10 * *$. Stark TJ, Arnold JD, Spector DH, Yeo GW. High-resolution profiling and analysis of viral and host small RNAs during human cytomegalovirus infection. J Virol. 2012; 86:226-235. This 
study used Next-generation sequencing to establish a high resolution profile of small RNA expression during productive HCMV infection, identified two novel HCMV miRNAs, and a cluster of cellular miRNAs that is up-regulated during infection. [PubMed: 22013051]

11. Hancock MH, Tirabassi RS, Nelson JA. Rhesus cytomegalovirus encodes seventeen microRNAs that are differentially expressed in vitro and in vivo. Virology. 2012; 425:133-142. [PubMed: 22305624]

12*. Ziegelbauer JM, Sullivan CS, Ganem D. Tandem array-based expression screens identify host mRNA targets of virus-encoded microRNAs. Nat Genet. 2009; 41:130-134. One of the first studies to identify miRNA targets experimentally. [PubMed: 19098914]

13**. Gottwein E, Corcoran DL, Mukherjee N, Skalsky RL, Hafner M, Nusbaum JD, Shamulailatpam P, Love CL, Dave SS, Tuschl T, et al. Viral microRNA targetome of KSHV-infected primary effusion lymphoma cell lines. Cell Host Microbe. 2011; 10:515-526. A seminal study that identified with unprecedented depth the KSHV and EBV miRNA targetome using highthroughput PAR-CLIP. The authors found that KSHV and EBV miRNAs target approximately 2000 cellular mRNAs each, many of which are involved in pathways relevant to virus pathogenesis. Moreover, KSHV and EBV miRNAs had 58\% common targets, suggesting that despite the absence of sequence conservation, the miRNAs from KSHV and EBV, two $\gamma$ herpesviruses with similar biology, have evolved to target the same genes and pathways. [PubMed: 22100165]

14**. Nachmani D, Stern-Ginossar N, Sarid R, Mandelboim O. Diverse herpesvirus microRNAs target the stress-induced immune ligand MICB to escape recognition by natural killer cells. Cell Host Microbe. 2009; 5:376-385. This study demonstrated for the first time that unrelated miRNAs from multiple herpesviruses target the same cellular gene to evade immunity mediated by NK cells. [PubMed: 19380116]

15*. Tirabassi R, Hook L, Landais I, Grey F, Meyers H, Hewitt H, Nelson J. Human cytomegalovirus US7 is regulated synergistically by two virally encoded microRNAs and by two distinct mechanisms. J Virol. 2011; 85:11938-11944. This study demonstrated a highly synergistic cooperation between two HCMV. [PubMed: 21900172]

16. Stern-Ginossar N, Saleh N, Goldberg MD, Prichard M, Wolf DG, Mandelboim O. Analysis of human cytomegalovirus-encoded microRNA activity during infection. J Virol. 2009; 83:1068410693. [PubMed: 19656885]

17. Selbach M, Schwanhausser B, Thierfelder N, Fang Z, Khanin R, Rajewsky N. Widespread changes in protein synthesis induced by microRNAs. Nature. 2008; 455:58-63. [PubMed: 18668040]

18. Lee SH, Kalejta RF, Kerry J, Semmes OJ, O'Connor CM, Khan Z, Garcia BA, Shenk T, Murphy E. BclAF1 restriction factor is neutralized by proteasomal degradation and microRNA repression during human cytomegalovirus infection. Proc Natl Acad Sci U S A. 2012; 109:9575-9580. [PubMed: 22645331]

19*. Chen C, Ridzon DA, Broomer AJ, Zhou Z, Lee DH, Nguyen JT, Barbisin M, Xu NL, Mahuvakar VR, Andersen MR, et al. Real-time quantification of microRNAs by stem-loop RT-PCR. Nucleic Acids Res. 2005; 33:e179. This paper established the guidelines to allow quick, robust, easy and sensitive detection and quantitation of miRNAs. [PubMed: 16314309]

20*. Grey F, Meyers H, White EA, Spector DH, Nelson J. A human cytomegalovirus-encoded microRNA regulates expression of multiple viral genes involved in replication. PLoS Pathog. 2007; $3: \mathrm{e} 163$. This is the first study to show that a viral miRNA targets a viral transcriptional activator, suggesting that viral miRNAs function in the establishment and maintenance of latency. [PubMed: 17983268]

21. Orom UA, Lund AH. Isolation of microRNA targets using biotinylated synthetic microRNAs. Methods. 2007; 43:162-165. [PubMed: 17889804]

22*. Karginov FV, Conaco C, Xuan Z, Schmidt BH, Parker JS, Mandel G, Hannon GJ. A biochemical approach to identifying microRNA targets. Proc Natl Acad Sci U S A. 2007; 104:19291-19296. This study introduced RIP-Chip, a first generation high-throughput biochemical method to identify miRNA targets that was more robust than previous bioinformatics approaches. [PubMed: 18042700]

23. Orom UA, Nielsen FC, Lund AH. MicroRNA-10a binds the $5^{\prime}$ UTR of ribosomal protein mRNAs and enhances their translation. Mol Cell. 2008; 30:460-471. [PubMed: 18498749] 
24. Licatalosi DD, Mele A, Fak JJ, Ule J, Kayikci M, Chi SW, Clark TA, Schweitzer AC, Blume JE, Wang X, et al. HITS-CLIP yields genome-wide insights into brain alternative RNA processing. Nature. 2008; 456:464-469. [PubMed: 18978773]

25*. Hafner M, Landthaler M, Burger L, Khorshid M, Hausser J, Berninger P, Rothballer A, Ascano M Jr. Jungkamp AC, Munschauer M, et al. Transcriptome-wide identification of RNA-binding protein and microRNA target sites by PAR-CLIP. Cell. 2010; 141:129-141. This study introduced PAR-CLIP, a second generation high-throughput biochemical method to identify miRNA targets that is more robust than previous RIP-Chip approaches. [PubMed: 20371350]

26. Pavelin J, Reynolds N, Chiweshe S, Wu G, Tiribassi R, Grey F. Systematic microRNA analysis identifies ATP6V0C as an essential host factor for human cytomegalovirus replication. PLoS Pathog. 2013; 9:e1003820. [PubMed: 24385903]

27. Thomas M, Lieberman J, Lal A. Desperately seeking microRNA targets. Nature Stuctural \& Molecular Biology. 2010; 17:1169-1174.

28*. Skalsky RL, Corcoran DL, Gottwein E, Frank CL, Kang D, Hafner M, Nusbaum JD, Feederle R, Delecluse HJ, Luftig MA, et al. The viral and cellular microRNA targetome in lymphoblastoid cell lines. PLoS Pathog. 2012; 8:e1002484. This study used PAR-CLIP and deep sequencing to perform a comprehensive survey of the mRNA targets of viral and cellular miRNAs in EBVinfected B cells. [PubMed: 22291592]

29. Mocarski ES, Kemble GW, Lyle JM, Greaves RF. A deletion mutant in the human cytomegalovirus gene encoding IE1(491aa) is replication defective due to a failure in autoregulation. Proc Natl Acad Sci U S A. 1996; 93:11321-11326. [PubMed: 8876134]

30*. Murphy E, Vanicek J, Robins H, Shenk T, Levine AJ. Suppression of immediate-early viral gene expression by herpesvirus-coded microRNAs: implications for latency. Proc Natl Acad Sci U S A. 2008; 105:5453-5458. This study found that the miRNAs of several different herpesviruses target viral transcriptional activators, suggesting that a common function amongst herpesvirus miRNAs is to regulate the establishment and maintenance of latency. [PubMed: 18378902]

31*. Umbach JL, Kramer MF, Jurak I, Karnowski HW, Coen DM, Cullen BR. MicroRNAs expressed by herpes simplex virus 1 during latent infection regulate viral mRNAs. Nature. 2008; 454:780783. This study found that HSV1 miRNAs expressed from the LAT transcript regulate latency by targeting viral ICP0 and ICP4 immediate-early transactivator genes. [PubMed: 18596690]

32. Prichard MN, Duke GM, Mocarski ES. Human cytomegalovirus uracil DNA glycosylase is required for the normal temporal regulation of both DNA synthesis and viral replication. J Virol. 1996; 70:3018-3025. [PubMed: 8627778]

33. Hansen TH, Bouvier M. MHC class I antigen presentation: learning from viral evasion strategies. Nat Rev Immunol. 2009; 9:503-513. [PubMed: 19498380]

34*. Stern-Ginossar N, Elefant N, Zimmermann A, Wolf DG, Saleh N, Biton M, Horwitz E, Prokocimer Z, Prichard M, Hahn G, et al. Host immune system gene targeting by a viral miRNA. Science. 2007; 317:376-381. This study identified the first miRNA-based immunoevasion mechanism by a HCMV miRNA. miR-UL112-1 was found to target the NK cell ligand MICB that is critical for NK cell killing of infected cells. [PubMed: 17641203]

35. Strong RK. Asymmetric ligand recognition by the activating natural killer cell receptor NKG2D, a symmetric homodimer. Mol Immunol. 2002; 38:1029-1037. [PubMed: 11955595]

36. Bekerman E, Jeon D, Ardolino M, Coscoy L. A role for host activation-induced cytidine deaminase in innate immune defense against KSHV. PLoS Pathog. 2013; 9:e1003748. [PubMed: 24244169]

37. Stern-Ginossar N, Gur C, Biton M, Horwitz E, Elboim M, Stanietsky N, Mandelboim M, Mandelboim O. Human microRNAs regulate stress-induced immune responses mediated by the receptor NKG2D. Nat Immunol. 2008; 9:1065-1073. [PubMed: 18677316]

38. Nachmani D, Lankry D, Wolf DG, Mandelboim O. The human cytomegalovirus microRNA miRUL112 acts synergistically with a cellular microRNA to escape immune elimination. Nat Immunol. 2010; 11:806-813. [PubMed: 20694010]

39. Kim Y, Lee S, Kim S, Kim D, Ahn JH, Ahn K. Human cytomegalovirus clinical strain-specific microRNA miR-UL148D targets the human chemokine RANTES during infection. PLoS Pathog. 2012; 8:e1002577. [PubMed: 22412377] 
40. Lamy L, Ngo VN, Emre NC, Shaffer AL 3rd, Yang Y, Tian E, Nair V, Kruhlak MJ, Zingone A, Landgren $\mathrm{O}$, et al. Control of autophagic cell death by caspase-10 in multiple myeloma. Cancer Cell. 2013; 23:435-449. [PubMed: 23541952]

41. Hoang B, Benavides A, Shi Y, Frost P, Lichtenstein A. Effect of autophagy on multiple myeloma cell viability. Mol Cancer Ther. 2009; 8:1974-1984. [PubMed: 19509276]

42. Zhang L, Wang A. Virus-induced ER stress and the unfolded protein response. Front Plant Sci. 2012; 3:293. [PubMed: 23293645]

43**. Hook LM, Grey F, Grabski R, Tirabassi R, Doyle T, Hancock MH, Landais I, Jeng S, McWeeney S, Britt W, et al. Cytomegalovirus miRNAs target secretory pathway genes to facilitate formation of the virion assembly compartment and reduce cytokine secretion. Cell Host \& Microbe. 2014; 15:363-373. This is the first study to show that multiple HCMV miRNAs coordinately regulate a cellular pathway, and that their concurrent (but not individual) inactivation has important functional consequences during HCMV infection. [PubMed: 24629342]

44. Huang Y, Qi Y, Ruan Q, Ma Y, He R, Ji Y, Sun Z. A rapid method to screen putative mRNA targets of any known microRNA. Virol J. 2011; 8:8. [PubMed: 21219658] 


\section{HIGHLIGHTS}

- More than 250 viral miRNAs have been identified, mostly in the herpesvirus family.

- $\quad$ RIP-Chip, PAR-CLIP and HITS-CLIP approaches have been instrumental in identifying potential miRNA target genes.

- Our understanding of the functions of herpesvirus miRNAs is just beginning to emerge.

- Despite absence of conservation, miRNAs from different herpesviruses may target same genes and pathways. 


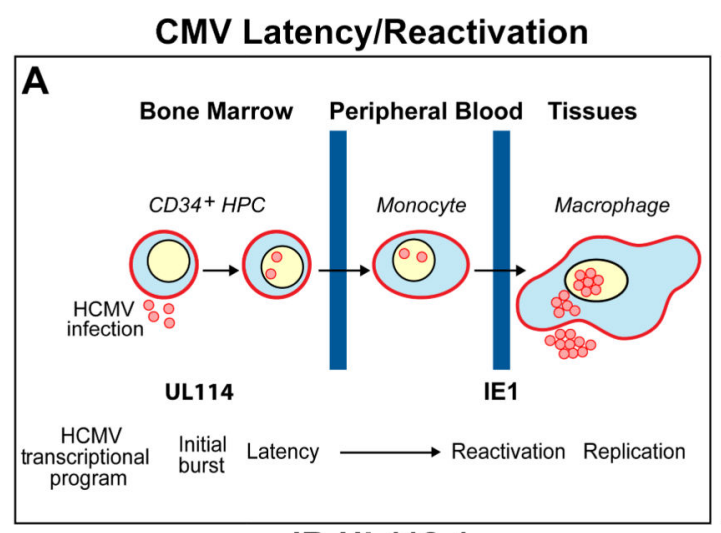

miR-UL112-1

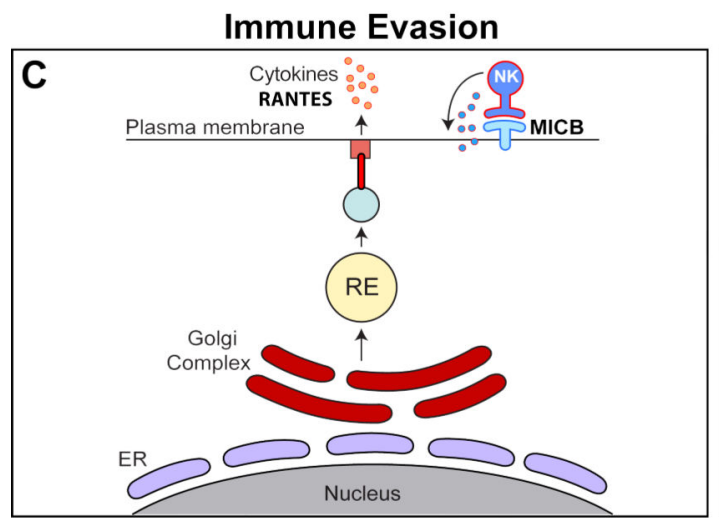

miR-UL148D-1

miR-UL112-1

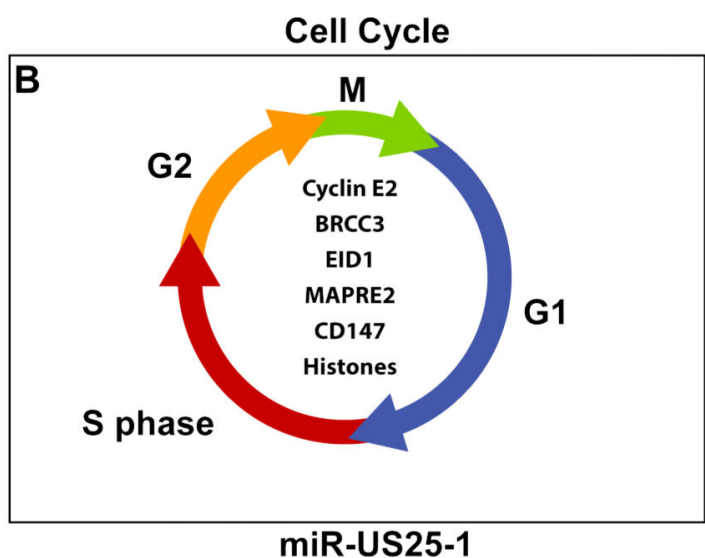

Secretory Pathway

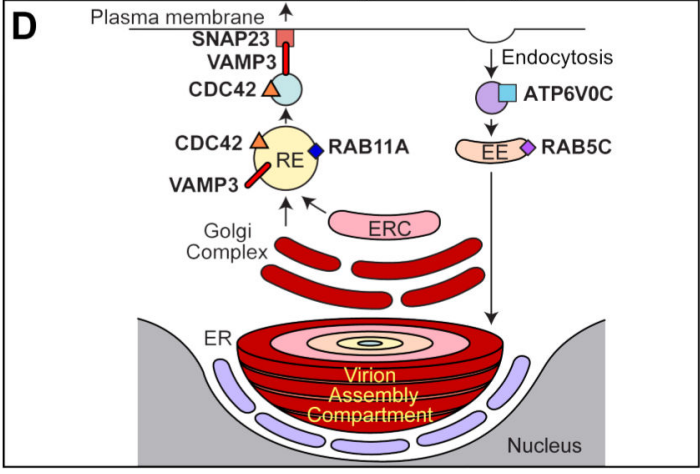

miR-UL112-1

miR-US5-1

miR-US5-2

miR-US25-1

Figure 1. Known targets and functions of HCMV miRNAs

(A) miR-UL112-1 targets viral factors UL114 (uracil DNA glycosylase) and IE1. Both proteins are thought to play a role in the establishment of latency and reactivation processes in hematopoietic lineage cells such as CD34+ HPCs, monocytes and macrophages. (B) miRUS25-1 targets cellular genes involved in cell cycle control including cyclin E2, BRCC3, EID1, MAPRE2, CD147 and histones. (C) HCMV miRNAs target genes involved in immune evasion. miR-UL148D-1 directly targets RANTES, a chemokine that recruits immune cells to the site of infection, while miR-UL112 targets the NK cell ligand MICB to prevent NK cell killing of infected cells. (D) HCMV miRNAs target the secretory pathway. miR-US25-1 targets the endosomal acidification complex component ATP6V0C while miRUL112, miR-US5-1 and miR-US5-2 coordinately target multiple secretory pathway genes including VAMP3, RAB5C, RAB11A, CDC42 and SNAP23, regulating the release of inflammatory cytokines and formation of the virion assembly compartment. 


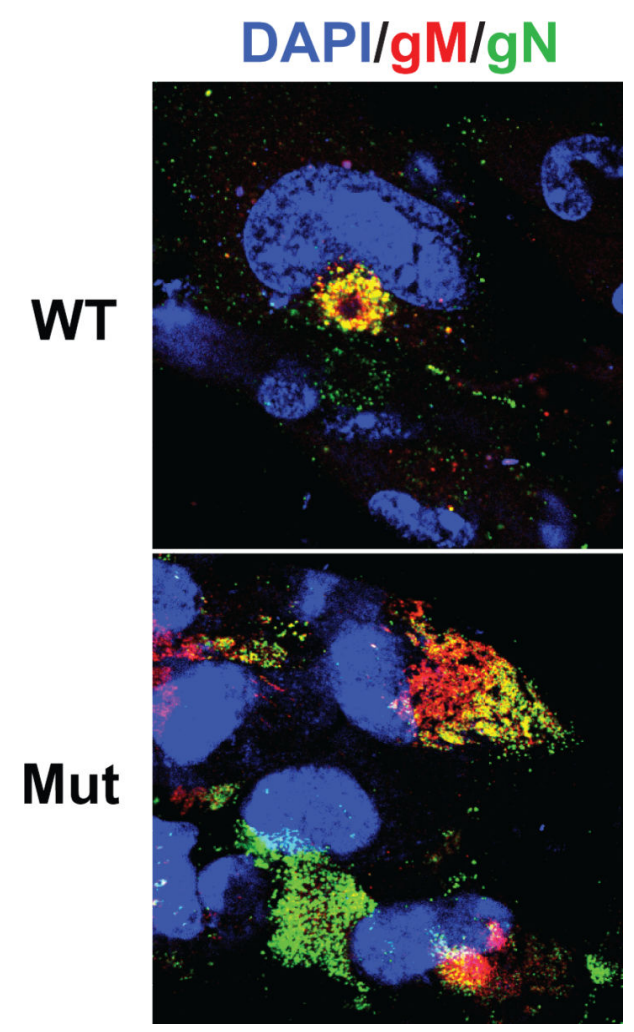

Figure 2. HCMV miRNAs that target components of the secretory pathway facilitate formation of the virion assembly compartment (VAC)

Normal human dermal fibroblasts were infected with an AD169 wild type virus (WT) or a virus in which miR-US5-1, miR-US5-2, and miR-UL112-1 have been mutated (Mut) at a multiplicity of infection of 0.1 . At 6 days post-infection, cells were analyzed by immunofluorescence for DNA (DAPI, blue), and the viral markers glycoprotein M (gM, red) and $\mathrm{N}$ (gN, green). While $\mathrm{gM}$ and $\mathrm{gH}$ co-localized in a compact perinuclear VAC during WT AD169 infection (top panel), these viral proteins localized in a diffuse pattern during infection with the triple miRNA mutant (bottom panel), suggesting that the VAC cannot form properly in the absence of these miRNAs. 


\section{Table 1}

Validated targets of HCMV miRNAs

\begin{tabular}{|c|c|c|c|c|c|}
\hline Target organism & miRNA & Target gene & Description & Validation method & Literature \\
\hline \multirow[t]{7}{*}{$\mathrm{HCMV}$} & miR-UL112-1 & IE72 & MIE IE72 & Luc, WB, KO & [30] \\
\hline & & UL120/121 & MIE region exons & Luc & [20] \\
\hline & & UL112/113 & Viral DNA synthesis & Luc & {$[20]$} \\
\hline & & UL114 & Viral DNA glycosylase & Luc, WB & [16] \\
\hline & & UL17/18 & MHC class I homologue & Luc & [44] \\
\hline & miR-US5-1 & US7 & Unknown function & Luc, WB (KO) & [15] \\
\hline & miR-US5-2 & US7 & Unknown function & Luc, WB (KO) & {$[15]$} \\
\hline \multirow[t]{25}{*}{ Human } & miR-UL112-1 & MICB & NK cell activating receptor & Luc, KO & [34] \\
\hline & & ZFP36L1 & Zinc-finger protein & Luc & [44] \\
\hline & & Transportin 1 & Subunit of karyopherin complex & Luc & [44] \\
\hline & & L7a & Ribosomal protein & Luc & [44] \\
\hline & & IL32 & Cytokine & Luc & [44] \\
\hline & & BclAF1 & $\begin{array}{l}\text { Apoptosis, transcriptional regulation, RNA } \\
\text { processing and nuclear export }\end{array}$ & Luc, WB, KO & {$[18]$} \\
\hline & & VAMP3 & $\begin{array}{l}\text { Vesicle-Associated Membrane Protein } 3 \text {, } \\
\text { cellubrevin }\end{array}$ & Luc, WB & {$[43]$} \\
\hline & & RAB5C & Member RAS oncogene family & Luc, WB, KO & [43] \\
\hline & & RAB11A & Member RAS oncogene family & Luc, WB, KO & [43] \\
\hline & & SNAP23 & Synaptosomal-associated protein, $23 \mathrm{kDa}$ & Luc, WB, KO & [43] \\
\hline & miR-US25-1 & CCNE2 & Cyclin E2 & $\begin{array}{l}\text { Luc, WB (KO) IP, WB } \\
(\mathrm{KO}), \mathrm{Luc}\end{array}$ & {$[2][26]$} \\
\hline & & H3F3B & Histone $\mathrm{H} 3$ variant & Luc & {$[2]$} \\
\hline & & TRIM28 & Transcriptional corepressor & Luc, WB (KO) & {$[2]$} \\
\hline & & ATPV016 & Component of the Vacuolar ATPase & Luc, WB (KO), Luc & {$[26]$} \\
\hline & & BCKDHA & Branched chain keto acid dehydrogenase E1 & IP, WB (KO) & [26] \\
\hline & & LGALS3 & galactosidase-binding, soluble, 3 (galectin3) & IP, WB (KO) & {$[26]$} \\
\hline & & SGSH & N-sulfoglucosamine sulfohydrolase & IP & {$[26]$} \\
\hline & & NUCB2 & Nucleobindin 2 & IP & {$[26]$} \\
\hline & miR-UL148D-1 & RANTES & Chemokine & Luc, RT-PCR, IP-WB & {$[39]$} \\
\hline & miR-US5-1 & VAMP3 & $\begin{array}{l}\text { Vesicle-Associated Membrane Protein } 3 \text {, } \\
\text { cellubrevin }\end{array}$ & Luc, WB & {$[43]$} \\
\hline & & RAB5C & Member RAS oncogene family & Luc, WB, KO & [43] \\
\hline & & RAB11A & Member RAS oncogene family & Luc, WB, KO & {$[43]$} \\
\hline & & SNAP23 & Synaptosomal-associated protein, $23 \mathrm{kDa}$ & Luc, WB, KO & [43] \\
\hline & miR-US5-2 & $\mathrm{CDC} 42$ & Cell division cycle 42 & Luc, WB & {$[43]$} \\
\hline & & SNAP23 & Synaptosomal-associated protein, $23 \mathrm{kDa}$ & Luc, WB, KO & [43] \\
\hline
\end{tabular}

Luc, luciferase assay; WB, Western blot; KO, infection with knockout virus; IP, immuno-precipitated; RT-PCR, reverse transcription PCR. 